\title{
DEL PRIMER AL SEGUNDO PLAN ESTRATÉGICO DE TURISMO EN CATALUÑA
}

\author{
Teresa Torres-Solé \\ Universidad de Lleida \\ https://orcid.org/0000-0002-2861-5213 \\ Mercè Sala-Ríos \\ Universidad de Lleida \\ https://orcid.org/0000-0001-7634-5951 \\ Mariona Farré-Perdiguer \\ Universidad de Lleida \\ https://orcid.org/0000-0002-2105-1101
}

\section{RESUMEN}

El artículo revisa las tendencias del sector turístico en Cataluña, desde la aprobación del primer Plan Estratégico de Turismo 2005-2010 hasta el segundo Plan Estratégico de Turismo 2013-2016 aún vigente, con el objetivo de orientar y hacer propuestas a incluir en el próximo Plan Estratégico de Turismo. Se observa que, aunque el segundo plan avanza en diversos aspectos respecto al primero, existen ciertos factores que no han sido corregidos durante su periodo de vigencia. El trabajo también aflora algunas tendencias actuales que deberían ser consideradas en futuras planificaciones turísticas.

Palabras clave: Sector turístico; Plan Estratégico de Turismo; Cataluña; tendencias turísticas.

\section{From the First to the Second Strategic Plan of Tourism in Catalonia}

\section{ABSTRACT}

This paper analyses the Catalan tourism sector progress and trend since the first Strategic Plan of Tourism in Catalonia 2005-2010 until the second Strategic Plan of Tourism of

Fecha de recepción: 9 de marzo de 2018

Fecha de aceptación: 6 de mayo de 2019

Departamento de Economía Aplicada. Universidad de Lleida. C/ Jaume II, 73. 25001 LLEIDA (España). E-mail: torres@econap.udl.cat,mercesa@econap.udl.cat,mariona.farre@econap.udl.cat 
Catalonia 2013-2016 with the aim of guiding and making proposals to be included in the next Tourism Strategic Plan. The results show that, despite the second plan has progressed in some aspects with respect to the first; there are several factors that have not been corrected. In this sense, the analysis that we carry out highlights some trends than should be included in future tourism plans.

Keywords: Tourism sector; Strategic Tourism Plan; Catalonia; tourism trends.

\section{INTRODUCCIÓN}

El clima, la posición geográfica y la accesibilidad han favorecido el desarrollo turístico de Cataluña durante los últimos sesenta años (Garay y Cànoves, 2009), configurándose como un importante destino turístico con una elevada oferta de productos y atractivos (véase el Atles del Turisme a Catalunya. Mapa Nacional de l'Oferta i els Productes Turístics) De este modo, el turismo resulta fundamental en la vertebración del tejido económico, social y cultural del territorio catalán, con destacadas aportaciones en materia de ingresos, generación de puestos de trabajo y contribución a nuevas oportunidades de desarrollo (López-Palomeque, 2009). Una aproximación a la dimensión del turismo muestra que Cataluña ha sido el principal destino para el $24 \%$ de los turistas extranjeros que llegaron a España durante el año 2016, seguido por Canarias con un 17,6\% (según datos de la Estadística de movimientos turísticos en frontera del INE) y también ha sido uno de los principales destinos turísticos de la Unión Europea ${ }^{1}$. Por otra parte, los siete mercados más tradicionales para Cataluña generaron el 62,4\% de las llegadas ${ }^{2}$ (Observatorio del Trabajo y Modelo Productivo de la Generalitat, 2017). Como indican Cànoves et al. (2016), los turistas internacionales son un elemento clave para la economía del sector, ya que su gasto medio es superior al del turismo nacional o excursionista. Ello explica que el turismo sea una importante fuente de riqueza de la economía catalana. Según los datos del Observatorio del Trabajo y Modelo Productivo de la Generalitat (2017), durante el año 2016, los 36,2 millones de turistas que llegaron a Cataluña realizaron un gasto de 20.862 millones de euros, de este modo, el sector del turismo alcanzaba la cifra del 12,6\% de la ocupación total en dicho año y aportaba el 12\% del PIB aproximadamente. Cabe indicar que la mayoría de estimaciones atribuyen al turismo aproximadamente entre el $10 \%$ y el $15 \%$ de la producción de Cataluña (López-Palomeque, 2009).

Colom et al. (2016a) destacan que además de la incidencia en el desarrollo económico, el turismo ha demostrado tener una gran resiliencia frente a la crisis global iniciada en el año 2008. El trabajo de Duro (2015) muestra como la evolución de las actividades turísticas fue

1 Según los datos publicados en julio de 2017 por la oficina de estadística comunitaria, Eurostat, España encabezó la lista de los principales destinos turísticos de la UE en el año 2015 con Canarias, que fue la principal región turística en la UE con 94 millones de pernoctaciones. Entre los diez primeros destinos turísticos también se situaba Cataluña con 75,5 millones de pernoctaciones, Islas Baleares con 62,2 millones y Andalucía con 61,4 millones.

2 Estos mercados son: Alemania, Bélgica, Francia, Italia, Países Bajos, Países nórdicos y Reino Unido. 
más favorable respecto a la actividad económica general durante el periodo de crisis entre 2008-2013. Los resultados obtenidos cifran en un 1,2\% el crecimiento turístico acumulado durante el periodo. Para el mismo ciclo la dinámica del PIB catalán se había reducido en una tasa del 4,8\%. Sin embargo, señala que el impacto del turismo no fue homogéneo desde el punto de vista de las marcas turísticas ${ }^{3}$. Barcelona, Costa de Barcelona, Costa Brava y Costa Dorada generaron casi el $85 \%$ de la actividad turística. Le siguieron a distancia, las marcas de interior, Paisajes de Barcelona, Tierras del Ebro y Tierras de Lleida, con el 8,5\% y las marcas de montaña Pirineos y Valle de Aran con el 6,5\%. De acuerdo con estos datos, se subraya el desequilibrio territorial del modelo turístico catalán.

La concentración de la actividad turística en pocas marcas es debido a que son destinos de litoral tradicionalmente orientados al producto sol y playa, con una estacionalidad muy elevada durante los meses de verano (Duro y Farré, 2015). La estacionalidad también es muy acusada en los destinos de montaña, como son las marcas Pirineos y Valle de Aran. Mientras que, en las marcas de interior, donde predomina el turismo rural, la estacionalidad se limita a los fines de semana y los puentes. Sin embargo, cabe señalar que, en una misma destinación, los picos de congestión son compatibles con largos periodos de baja actividad turística (Departament d'Empresa i Coneixement, 2011). Para el caso de la marca Barcelona, Duro y Rodríguez (2015) afirman que la estacionalidad de la demanda no es especialmente elevada. Su estudio destaca que Barcelona ha crecido turísticamente en estas últimas décadas de manera muy significativa, lo cual le ha permitido alcanzar una posición privilegiada a escala internacional. Los datos del informe anual de la red European Cities Marketing (2017) la sitúan en la quinta posición a escala europea respecto al número de pernoctaciones, por detrás de Londres, París, Berlín y Roma. El informe concluye que las ciudades europeas siguen siendo los destinos turísticos más atractivos para los visitantes de todo el mundo.

Ante el elevado perfil turístico que muestra Cataluña, y con una población de 7,54 millones de habitantes (según datos de Idescat), hay que tener presente la incidencia que ejerce sobre la población residente. Por este y otros motivos, resulta evidente la necesidad de contar con organismos dedicados a la promoción de la imagen turística de Cataluña, pero también que velen por una correcta y adecuada gestión de los flujos y la actividad turística del territorio (Colom et al., 2016b). Es necesario que las iniciativas públicas y privadas vayan conjuntamente coordinadas para consolidar y mejorar la posición en el contexto internacional. Recordemos que la Administración Pública tiene entre sus competencias la promoción exterior del turismo como uno de los factores claves de la política y de la posición que ocupa el sector turístico español (Rivas, 2017). En consecuencia, la estrategia de promoción se planifica, se desarrolla y se ejecuta desde la administración, a través del Instituto de Turismo de España y los órganos adscritos y dependientes de éste (Secretaria General de Turismo, 2007). En Cataluña la competencia del turismo

3 La Ley 13/2002, de 21 de junio, de Turismo de Cataluña establece como primer objetivo de la Generalitat promover Cataluña como una marca turística global, que integre y respete el resto de marcas catalanas (artículo 28). Actualmente la Dirección General de Turismo de la Generalitat reconoce la existencia de nueve marcas turísticas como representativas de la diversidad y homogeneidad de los productos turísticos territoriales. 
corresponde al Departamento de Empresa y Conocimiento, del cual depende la Dirección General de Turismo de la Generalitat de Cataluña ${ }^{4}$.

Entre las funciones de esta Dirección cabe destacar las siguientes, diseñar, coordinar y ejecutar las políticas para el fomento de la competitividad del sector turístico, la innovación y la calidad de los productos turísticos de Cataluña y elaborar los instrumentos de planificación para que la actividad turística sea equilibrada y sostenible en el territorio. Así lo expresa Arnandis-i-Agramunt (2018), la experiencia demuestra que los espacios turísticos que han sido planificados inadecuadamente bien sea por la presión de la demanda en la configuración del destino o por los impulsos de los sectores afectados, sufren a largo plazo complicaciones de tipo ambiental y social.

La Dirección General de Turismo trabaja conjuntamente con un equipo multidisciplinar de profesionales en la elaboración de los Planes Estratégicos de Turismo, que se elaboran mediante un proceso metodológico consultivo y participativo. El primer Plan Estratégico de Turismo 2005-2010 pretendía ser un instrumento de coordinación y gobernanza para el Gobierno de la Generalitat, con el propósito de ofrecer fórmulas de cooperación y optimización en el uso de los recursos al sector público y servir al sector privado como marco de referencia para tomar decisiones (Secretaria de Comerç i Turisme, 2005). Esta acción de planificación estratégica, pionera en España, ofrecía una visión integral y transversal del turismo, e incluía líneas de actuación en materia de renovación y diversificación del turismo en Cataluña, que en esos momentos ya mostraba signos de madurez y regresión (Colom et al., 2016a). El desarrollo del primer Plan Estratégico de Turismo se consideró una verdadera "hoja de ruta" para la política turística en ese periodo. Antes de finalizar su periodo de vigencia, se empezó a trabajar en la opción de la renovación del Plan. No obstante, la irrupción de la crisis y el cambio de gobierno con las elecciones autonómicas a finales de 2010, motivaron el encargo de un nuevo plan estratégico para la nueva legislatura (López-Palomeque y García, 2016).

En junio de 2013 el gobierno catalán aprobó el Plan Estratégico de Turismo de Cataluña 2013-2016 y Directrices Nacionales de Turismo 2020 sucesor del anterior. En él se define el modelo turístico de Cataluña a medio plazo y se orienta la política turística para la Generalitat, así como para los agente públicos y privados durante los próximos años. El documento también establece las Directrices Nacionales de Turismo para el horizonte 2020 (Generalitat de Cataluña, 2013). Dos planes que como afirman López-Palomeque y García (2016) marcaron la hoja de ruta de la política turística para los próximos años.

En este contexto es donde se sitúa el objetivo de nuestro trabajo, en el que se revisan los avances y nuevas tendencias del turismo en Cataluña desde la aprobación del primer Plan Estratégico de Turismo hasta el segundo plan aún vigente y próximo a renovar, con la finalidad de orientar y hacer propuestas a incluir en futuras planificaciones turísticas. Dicho objetivo se pretende alcanzar con el enfoque del Análisis de Políticas Públicas. En concreto el propósito de la evaluación realizada es triple: a) Elaborar un diagnóstico sobre la planificación del sector turístico en Cataluña, b) Identificar el grado de consecución de

4 Según el artículo 171 del Estatuto de Autonomía, la Generalitat de Cataluña tiene la competencia plena en materia de turismo. 
los objetivos de ambos planes estratégicos del turismo, c) Ofrecer orientaciones a tener en cuenta en el próximo Plan Estratégico del Turismo.

La estructura del artículo es la siguiente, a continuación se describe la metodología, en el apartado siguiente se realiza un diagnóstico sobre la situación del sector turístico catalán y su evolución entre los periodos de vigencia de ambos planes estratégicos. Tras este, en el cuarto se analizan los objetivos de ambos documentos, para detectar los déficits que presenta el sector. En el quinto apartado se ofrecen algunas orientaciones para el diseño de la política turística que deberían tenerse en cuenta en el futuro Plan Estratégico de Turismo en Cataluña. El trabajo finaliza con las conclusiones.

\section{METODOLOGÍA}

El alcance de nuestro objetivo se plantea mediante el enfoque del Análisis de Políticas Públicas, en este caso, centrado en los dos Planes Estratégicos de Turismo aprobados hasta el momento en Cataluña. Según la OCDE (2010) esta evaluación consiste en un proceso que permite determinar el valor o significación de un programa y debe aportar información creíble y útil para su incorporación en la de toma de decisiones.

La metodología del Análisis de las Políticas Públicas para el estudio de las políticas turísticas ha sido aplicada en el trabajo de Santos-Lacueva et al. (2017). Este se centra en el análisis de los tres últimos planes turísticos aprobados por el gobierno de España. En él se destaca que dicha metodología permite analizar cuestiones clave en la planificación turística a partir de los documentos de política turística y comprender cuál es la perspectiva de los poderes públicos al respecto. De este modo permite detectar deficiencias en la planificación con el objetivo de mejorar futuros instrumentos de intervención y observar la evolución de los conceptos estratégicos en dichas políticas turísticas. Como indica Velasco (2011), los planes son un elemento clave en el análisis de las políticas turísticas.

Con anterioridad, la citada autora en su trabajo (Velasco, 2008) aplica esta metodología al estudio de los distintos planes de acción para apoyar el desarrollo turístico, que han sido aprobados por el gobierno general del Estado durante la etapa 1952-2006. En él se destacan los retos que surgen según evoluciona el modelo turístico del país y los aspectos que aparecen, reiteradamente, como problemas del turismo. Entre las cuestiones que aún hoy siguen apareciendo como conflictos a solucionar, el estudio destaca el problema de la formación turística, la falta de instrumentos de planificación, la falta de control sobre la prestación de servicios en espacios que se convierten en destinos turísticos o los problemas medioambientales.

En nuestro caso, el proceso seguido para el análisis se ha basado en las aportaciones teóricas de organismos nacionales como el Institut Català d'Avaluació de Polítiques Públiques-IVALUA (IVALUA, 2009) o internacionales como el Banco Mundial (2006), Gertler et al. (2011) y la OCDE (2010). En concreto se ha llevado a cabo una evaluación externa, esto es por un equipo de evaluadores externos, formado por las autoras del trabajo, con experiencia en el estudio del sector turístico y que actúan con un elevado grado de independencia. La función de dicha evaluación es formativa, lo cual nos ha permitido obtener información y hacer propuestas a incluir en el siguiente Plan Estratégico de Turismo. Esta aproximación se ha realizado ex-post, tras finalizar el periodo de vigencia de ambos planes 
correspondientes a los periodos 2005-2010 y 2013-2016. Ello nos ha facilitado valorar el impacto de estos planes, esto es analizar su eficacia y determinar en qué medida se alcanzan sus objetivos. A tal efecto, se ha desarrollado el siguiente plan de trabajo. La primera fase ha consistido en recoger información a partir del análisis documental de los planes estratégicos, memorias de la Dirección General de Turismo y otros documentos de política turística de Cataluña. Posteriormente, se ha llevado a cabo el análisis de datos cualitativo a partir de la información que se ha obtenido en el trabajo de campo (procedente de Exeltur, Ayuntamiento de Barcelona, Idescat, Eurostat y Observatorio del Trabajo y Modelo Productivo de la Generalitat, entre otros). Todo ello, nos ha facilitado evaluar cuáles son los objetivos que persiguen ambos Planes Estratégicos de Turismo, con qué programas se pretenden conseguir, en qué grado se han alcanzado y detectar nuevas tendencias del turismo en Cataluña, que es necesario sean consideradas en el futuro Plan Estratégico.

\section{DIAGNÓSTICO DEL TURISMO SEGÚN AMBOS PLANES ESTRATÉGICOS}

A partir de la revisión del documento del primer y del segundo Plan Estratégico de Turismo se ha realizado el siguiente diagnóstico del turismo en Cataluña. En la justificación del primer plan (2005-2010) se indica que pese a la larga experiencia turística que tiene Cataluña, el sector debe hacer frente a los retos del contexto internacional, a los cambios en los hábitos de consumo y al surgimiento de nuevas destinaciones competidoras. Se asume que el turismo debe ofrecer atractivos de calidad y se reclama una adecuada coordinación y cooperación entre los múltiples sectores públicos y privados que intervienen en el ámbito turístico. Ello obedece a que el turismo se ha convertido en una de las prioridades estratégicas en esta comunidad.

Por su parte, el Segundo Plan de Turismo (2013-2016) afirma que Cataluña es, en conjunto, un destino maduro, diverso, competitivo y en expansión. Un destino en el que la gran dimensión que ha alcanzado el sector turístico ya no permite renunciar a un modelo basado en la cantidad, pero en el que es necesario un impulso decidido para mejorar la calidad mediante una apuesta por un turismo de mayor valor añadido en términos económicos, culturales y ambientales. De este modo el segundo plan prioriza las actuaciones enfocadas al valor sostenible y a la competitividad que permitan aumentar los indicadores de calidad sin renunciar a un modelo turístico inevitablemente ligado a la cantidad.

Véase que el segundo plan, a diferencia del primero que centraba el enfoque en el contexto internacional y en la capacidad para atraer mayor número de turistas, destaca la importancia de los factores de ámbito interno como la sostenibilidad y la calidad, no con el objetivo de incrementar la cantidad de turistas sino los ingresos que estos generan ${ }^{5}$. En el segundo plan se destaca la reorientación desde la cantidad a la calidad, de recibir muchos turistas a fidelizar clientes sostenibles, de disponer de muchos recursos turísticos a crear una cartera equilibrada y complementaria de productos turísticos.

Para determinar hasta qué punto se alcanza esta reorientación hacia la calidad, fidelización y diversificación turística, se ha analizado la posición que ocupa Cataluña en los

5 El primer plan también pretendía una mayor calidad y sostenibilidad del turismo, sin embargo, ponía el énfasis en que se acompañara de una mayor entrada de turistas. 
indicadores de competitividad turística ${ }^{6}$ por comunidad autónoma que elabora Exceltur (2016a). Los datos, cifras de 2014, indican que ocupa la primera posición en los ámbitos Visión de marketing estratégico y apoyo comercial ${ }^{7}$ y Diversificación y estructuración de productos turísticos ${ }^{8}$. Se sitúa en la segunda posición del ranking autonómico en el ámbito del Turismo como prioridad política y su gobernanza $a^{9}$, ocupa la tercera posición en Accesibilidad y conectividad por medios de transporte, la quinta en Desempeño: resultados económicos y sociales, la octava posición en Atracción de talento, formación y eficiencia de los recursos humanos ${ }^{10}$ y la posición onceaba en Ordenación y condicionantes competitivos del territorio y los espacios turísticos ${ }^{11}$. Todo ello lleva a que Cataluña ocupe la primera posición del ranking en la tabla de resultados generales de los indicadores de competitividad turística analizados de manera global, con un índice de 116 en relación a la media del año $2010=100$. Sin embargo, pese a estos buenos resultados, cabe destacar la pérdida de posición en aspectos muy relevantes como la Ordenación y condicionantes competitivos del espacio turístico. El citado informe de Exceltur destaca que están surgiendo problemas de superación de la capacidad de carga ente el impulso del alquiler irregular de apartamento de uso turístico. Sin duda, el fuerte aumento de la demanda extranjera, que ha pasado de los 14,6 millones del año 2005 hasta los más de 19 millones del año 2017 (Observatorio del Trabajo y Modelo Productivo de la Generalitat, 2017), ha favorecido esta peor situación relativa de los factores ambientales y de ordenación del territorio.

Se observa que cada año llegan más turistas y ello ha generado un debate sobre los límites del turismo y su sostenibilidad. Existe cierto consenso internacional en el hecho de que no se ha logrado un equilibrio entre el crecimiento de la actividad turística y el desarrollo socioeconómico y ambiental (Miguel et al., 2014). Es por ello que Santos-Lacueva et al. (2017) afirman que resulta imprescindible analizar y ampliar los instrumentos de acción pública que favorezcan la sostenibilidad futura del sector y destacan la inevitable intervención pública, cuya eficacia y pertinencia son claves para determinar el éxito y la sostenibilidad futura de los destinos. Si nos centramos en el sector del turismo en Cataluña, son pocos los estudios empíricos que analizan su nivel de sostenibilidad, entre ellos podemos citar el de Torres-Delgado (2010) aplicado a cuatro municipios turísticos, el de Cots et al. (2010) que analiza el estado de la cuestión en relación a las empresas de turismo

6 Entendiendo la competitividad turística como la capacidad de incrementar de forma sostenible la productividad del sistema turístico a largo plazo.

7 En este ámbito se incluyen las estrategias de marketing, incluido el on-line, su dotación presupuestaria y la gestión del marketing y la promoción institucional. Cataluña muestra un valor de 131,1 sobre un valor de 100 para el año 2010.

8 Se refiere a la gestión integral y diversificación de la oferta y a la cualificación de la oferta de alojamiento y restauración. El índice de 2014 es de 128,9 para Cataluña, con un valor de 100 en el año 2010.

9 En este ámbito se valoran aspectos como la prioridad política (posición del turismo en la escala organizativa, esfuerzo presupuestario o coordinación inter-consejería), la visión estratégica, el seguimiento de los resultados económicos y la apuesta por la innovación, la institucionalización de la cooperación con el sector privado, la eficacia en la gestión de las competencias turísticas y la coordinación interadministrativa. Cataluña con un valor de 117,2 sigue tras la Rioja con un valor de 117,8 , respecto a la media $=100$ de 2010 .

10 El índice que valora la productividad de los trabajadores turísticos, su dotación de capital humano, estabilidad en el empleo y calidad del sistema formativo se ha reducido desde la media=100 de 2010 a 99,1 en 2014.

11 En el año 2014 el índice es de 98 para valorar la protección del territorio, la densidad urbana en los destinos, el atractivo de los espacios públicos, el compromiso ambiental y otros servicios de soporte. 
activo y la sostenibilidad en Cataluña, a semejanza de Romagosa et al. (2011) que evalúan el papel adjudicado al sector turístico en el marco de la Estrategia para el Desarrollo Sostenible de Cataluña, el de Balagué y Navinés (2012) centrado en la Costa Brava, el de Torres, et al. (2013) aplicado a las marcas turísticas, el de Gabarda et al. (2015) sobre la Costa Brava, el de Torres et al. (2015) aplicado a los ámbitos turísticos catalanes, el de Soliguer (2017) que concluye que la política turística en Cataluña se halla enmarcada en un programa económico ideológicamente alejado de otros modelos más cercanos al desarrollo sostenible o el más reciente de Garay et al. (2018) donde el análisis de la implementación de la sostenibilidad en el sector turístico se aplica a las agencias minoristas catalanas.

Como aspectos negativos, el segundo plan destaca, por una parte, que en muchos ámbitos del turismo ha predominado una visión especulativa a corto plazo que ha invadido buena parte de los mejores paisajes de Cataluña, con un urbanismo agresivo y una arquitectura de baja calidad. Por otra parte, el plan señala que Cataluña dispone de unas seiscientas mil plazas de alojamiento turístico regularizado y calcula que el número de plazas de alojamiento en viviendas de uso turístico no regularizado, sin control estadístico, fiscal o de calidad turística oficial es superior a un millón de camas. En el ámbito positivo indica que el sector tiene una gran capacidad para arrastrar a los demás sectores productivos, generar divisas y en el contexto de crisis que se vivía durante su elaboración, era uno de los pocos sectores importantes con perspectivas de crecimiento a corto plazo.

Encontramos en este punto ciertos avances entre el primer y segundo plan. La referencia al urbanismo agresivo, a las viviendas turísticas no regularizadas y a la capacidad del turismo para favorecer un cambio en la coyuntura económica. En el primer caso, cabe destacar que el plan estratégico vigente entre 2005-2010 se elaboró en la etapa de expansión de la burbuja inmobiliaria, donde el sector de la construcción era el motor de crecimiento de la economía. En él se evitaba cualquier referencia a los efectos negativos que este sector generaba en el turismo como son la existencia de ciertos paisajes litorales con un exceso de oferta y una cantidad importante de plazas de alojamiento turístico en la costa (Aledo, 2008). Al respecto, entre las debilidades del sector en el segundo plan se mencionan la degradación del paisaje (materia prima del turismo) y el exceso y la obsolescencia de la oferta de alojamiento en algunos ámbitos como el litoral, así como los bajos niveles de eficiencia energética en las edificaciones.

El segundo plan apunta uno de los problemas turísticos de mayor actualidad en determinadas zonas como Barcelona. Informes recientes como Exceltur (2017) destacan que la primera causa de congestión declarada por los ciudadanos, en destinos vacacionales y urbanos de éxito, es el desbordante, irregular y aún descontrolado crecimiento de oferta de viviendas turísticas distribuidas por plataformas tecnológicas de contacto entre iguales, que en apenas 6 años superan toda la oferta reglada existente.

Como aspecto positivo el segundo plan destaca la capacidad del turismo para arrastrar a los demás sectores productivos. Las cifras del estudio de Baró (2010) sobre el impacto del gasto turístico en el conjunto de la economía catalana indican que genera un efecto directo sobre la producción de $11.007,7$ millones de euros ${ }^{12}$ y un efecto indirecto de

12 Los efectos directos se concentran en las actividades Restauración establecimientos de bebidas y comidas (37,5\% del total), Transporte aéreo (12\%), Hoteles, Campins y otros tipos de alojamientos $(11,3 \%)$ y Comercio y reparaciones $(10,2 \%)$, como más importantes. 
5.188,4 ME sobre el conjunto de sectores productivos catalanes ${ }^{13}$. El efecto total por las compras hacia el resto de España es de $1.985,1 \mathrm{ME}$ y el efecto total sobre las importaciones hacia el resto del mundo de 2.000 ME. En este punto, el trabajo de Sala et al. (2014) afirma que el impacto de la demanda turística sobre la economía será diferente para las comunidades autónomas que mayoritariamente reciben turismo residente de las que lo reciben mayoritariamente no residente. En el caso de Cataluña, con una elevada cifra de turistas no residentes, este turismo ejercerá un efecto arrastre sobre la actividad económica, que a su vez arrastrará al turismo interno generando efectos positivos sobre la actividad económica. En segundo lugar, el citado trabajo destaca un posterior efecto arrastre del turismo sobre el territorio, desde aquellas comunidades con mayor número de llegadas internacionales que serán las primeras en notar el efecto expansivo del turismo y que generará un proceso de arrastre que acabará beneficiando a las comunidades mayormente receptoras de turismo interno.

Por último, destacamos que el segundo Plan Estratégico de Turismo no se limita a hablar de producto turístico, e introduce el concepto "experiencias" turísticas. Así por ejemplo se indica en la introducción "Este plan estratégico tendrá que dar pasos del hardware al software. De ser un destino de vacaciones a convertirse en un país de experiencias" (Generalitat de Cataluña, 2013, p. 6). Destaca como uno de los pilares de futuro, que "Cataluña es un destino rico en recursos turísticos gracias a la calidad y a la diversidad de su patrimonio natural y cultural. El fundamento del sector turístico reside en la capacidad de sus actores para transformar estos recursos en productos turísticos vendibles que acaben siendo experiencias gratificantes para los usuarios. El futuro de nuestro sector pasa por innovar de forma permanente en el desarrollo de nuevas experiencias para disfrutar de nuestro patrimonio natural y cultural, una labor en la que el papel de los pequeños y medianos emprendedores es clave" (Generalitat de Cataluña, 2013, p. 15).

Se observa en el segundo plan una clara referencia al concepto de "experiencias" en consonancia con el modelo económico actual que surge a partir de los noventa y que se manifiesta con una acelerada internacionalización de la economía. En este modelo económico se produce un cambio a nivel global, la economía de experiencias se abre paso ante la predecesora economía de servicios, en la que el nuevo objetivo es ofertar experiencias únicas que interesen al consumidor, de un modo individualizado (Araújo, 2015). El consumo pasa a ser el disfrute de sensaciones, más aún en el ámbito del turismo. Como señala Niño-Becerra (2015), los noventa supusieron una profundización de la idea del consumo, en consonancia con la obtención de algo más, pero un algo más inmaterial, que se añade al aspecto material que el bien en sí supone, idea esta que ya no se abandona en las décadas siguientes. Otra de las características del actual modelo de consumo que también destaca el citado autor es la inmediatez: todo tiene que ser lo más a corto plazo posible y lo más inmediato que permita la tecnología. Es por ello que entre las debilidades que destaca el segundo plan se observa el bajo uso de las nuevas tecnologías de la comunicación y los

13 Once actividades de la economía catalana concentran el $73 \%$ de los efectos indirectos del gasto turístico sobre la producción: Servicios empresariales (14,8\%), Comercio y reparaciones (13,5\%), Servicios inmobiliarios $(8,6 \%)$, Industria de otros productos de alimentación y tabaco $(5,9 \%)$, Mediación financiera (4,9\%), industrias cárnicas (4,8\%), Distribución luz, gas, agua (4,7\%), Elaboración de bebidas (4,2\%), Agricultura y ganadería (4\%), Construcción $(3,9 \%)$ y Correos y telecomunicaciones $(3,6 \%)$. 
bajos niveles de innovación, aspectos que favorecen el surgimiento de nuevas experiencias y la inmediatez.

\section{OBJETIVOS Y PROGRAMAS DE ACTUACIÓN DE AMBOS PLANES ESTRA- TÉGICOS}

El primer Plan Estratégico de Turismo señalaba diez objetivos para el periodo 20052010. Por su parte, el segundo Plan Estratégico de Turismo plantea cinco retos que debe afrontar el sector para equilibrar la cantidad con la calidad y para atraer un turismo de mayor valor añadido que permita asegurar la sostenibilidad económica, social y ambiental de cara al futuro, según se observa en el cuadro 1 .

\section{Cuadro 1 \\ OBJETIVOS DEL PLAN ESTRATÉGICO DE TURISMO (2005-2010) Y RETOS DEL PLAN ESTRATÉGICO DE TURISMO (2013-2016)}

\begin{tabular}{|c|c|}
\hline $\begin{array}{l}\text { Objetivos del Plan Estratégico de Turismo } \\
\qquad(2005-2010)\end{array}$ & $\begin{array}{l}\text { Retos del Plan Estratégico de Turismo } \\
\qquad(2013-2016)\end{array}$ \\
\hline $\begin{array}{l}\text { Mejorar la gestión integral del turismo y la } \\
\text { colaboración público-privada para consolidar } \\
\text { el posicionamiento turístico e incrementar los } \\
\text { ingresos por turista. }\end{array}$ & \multirow{2}{*}{$\begin{array}{l}\text { Reto de la gobernanza. Aspectos como } \\
\text { la fragmentación del sector público, la } \\
\text { concurrencia competencial del turismo entre } \\
\text { diferentes administraciones, la atomización } \\
\text { del sistema asociativo de las pymes turísticas, } \\
\text { o una cultura de baja colaboración entre sector } \\
\text { público y privado son aspectos que condicionan } \\
\text { el desarrollo de un nuevo modelo turístico. } \\
\text { Se necesita un enfoque que acompañe el } \\
\text { espíritu emprendedor y facilite el desarrollo } \\
\text { de la actividad empresarial y del empleo del } \\
\text { sector con una orientación hacia los mercados } \\
\text { internacionales. }\end{array}$} \\
\hline $\begin{array}{l}\text { Ordenar el desarrollo turístico según las } \\
\text { capacidades, potencialidades y la planificación } \\
\text { del territorio. }\end{array}$ & \\
\hline $\begin{array}{l}\text { Incrementar la competitividad del sector } \\
\text { turístico mediante una mejora de la calidad y la } \\
\text { innovación tecnológica. }\end{array}$ & \multirow{2}{*}{$\begin{array}{l}\text { Reto del desarrollo sostenible. Aspectos como } \\
\text { un urbanismo agresivo, el poco respeto hacia el } \\
\text { paisaje, la creación de camas turísticas sin valor } \\
\text { añadido, la falta de innovación y reinversión } \\
\text { o el monocultivo turístico han conllevado en } \\
\text { ciertos destinos un coste económico, social y } \\
\text { ambiental superior a los beneficios. Por lo tanto, } \\
\text { deben identificarse los destinos o empresas } \\
\text { que fundamentan su modelo en criterios } \\
\text { insostenibles, para influir en un proceso de } \\
\text { transformación hacia modelos sostenibles. }\end{array}$} \\
\hline $\begin{array}{l}\text { Incrementar la calidad y la diversidad de la } \\
\text { oferta turística con la perspectiva de alcanzar } \\
\text { una mayor sostenibilidad económica, social y } \\
\text { cultural. }\end{array}$ & \\
\hline
\end{tabular}




\begin{tabular}{|c|c|}
\hline $\begin{array}{r}\text { Objetivos del Plan E } \\
(2005\end{array}$ & 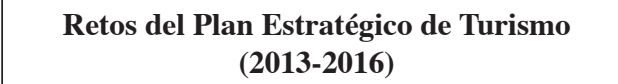 \\
\hline ca turística & \multirow{2}{*}{$\begin{array}{l}\text { Reto de creación de nuevos productos } \\
\text { turísticos. Cataluña es rica en recursos } \\
\text { turísticos, pero aun pobre en productos turísticos } \\
\text { estructurados, innovadores, competitivos y } \\
\text { vendibles, sobre todo en el ámbito internacional. } \\
\text { Hay mucho camino por recorrer en el desarrollo } \\
\text { de productos y experiencias turísticas, donde } \\
\text { el tiempo disponible, la combinación de } \\
\text { diferentes recursos y las nuevas tecnologías de } \\
\text { comunicación son factores clave. }\end{array}$} \\
\hline $\begin{array}{l}\text { Potenciar la calidad de la form } \\
\text { especializada y su adaptación a la realida } \\
\text { mercado, fomentar la calidad de los pues } \\
\text { trabajo del sector. }\end{array}$ & \\
\hline $\begin{array}{l}\text { de turismo que sea } \\
\text { ble. }\end{array}$ & \multirow{2}{*}{$\begin{array}{l}\text { Reto del conocimiento y la inteligencia. La } \\
\text { complejidad del sector unida a la dependencia } \\
\text { de muchas fuentes de información externas, } \\
\text { hace que la Dirección General de Turismo } \\
\text { no disponga de información suficientemente } \\
\text { extensa, homogénea y estable para desarrollar } \\
\text { adecuadamente su labor. Las posibilidades y las } \\
\text { fuentes de información actuales son muy amplias } \\
\text { y dispersas, y debe potenciarse una unidad de } \\
\text { conocimiento para ponerla a disposición de todo } \\
\text { el sector turístico. }\end{array}$} \\
\hline $\begin{array}{l}\text { no es un } \\
\text { ritorio y } \\
\text { sectores }\end{array}$ & \\
\hline las & \multirow{2}{*}{$\begin{array}{l}\text { Reto de la excelencia. El uso avanzado de las } \\
\text { nuevas TIC, el conocimiento de los idiomas } \\
\text { la formación, la atracción de talento, la gestión } \\
\text { de la innovación, la actitud emprendedora o la } \\
\text { calidad del servicio son asignaturas pendientes } \\
\text { del sector turístico que representan frenos } \\
\text { importantes para alcanzar los niveles de } \\
\text { excelencia necesarios en un entorno de crisis y } \\
\text { alta competencia. }\end{array}$} \\
\hline $\begin{array}{l}\text { o normativo a las necesidades } \\
\text { is del sector para garantizar su }\end{array}$ & \\
\hline
\end{tabular}

Fuente: Secretaria de Comerç i Turisme (2005) y Generalitat de Cataluña (2013).

Par alcanzar estos objetivos el primer plan establecía diez programas ${ }^{14}$, que afectaban al conjunto de agentes del sector turístico (Generalitat, administraciones del Estado y locales, sector privado, universidades, centros de formación e investigación y sociedad civil), de los que dependían cuarenta y ocho acciones.

Entre las acciones realizadas en este primer plan destacamos las siguientes. En el año 2007 se encargó un estudio sobre experiencias europeas de turismo sostenible aplicables a Cataluña (Sabaté, 2007) y se creó la primera facultad de Turismo en la Universidad

14 1- Territorio, paisaje y sociedad. 2- Fomento e integración de productos turísticos. 3- Identificación y potenciación de los rasgos diferenciales de la oferta turística catalana. 4- Marketing y promoción. 5- Modernización y mejora de la información turística. 6- Calidad. 7- Formación y recursos humanos en turismo. 8Investigación aplicada, tecnología e innovación. 9- Fortalecimiento institucional y sectorial y marco normativo. 10- Comunicación y sensibilización. 
de Girona, también estaba prevista la creación del Instituto de Investigación de Turismo de Cataluña (IRTUCA). Al año siguiente se aprobó el Pla de Desenvolupament Turístic (PLADETUR) que ponía al servicio de los diferentes agentes públicos y privados del sector turístico catalán un conjunto de programas de incentivos individuales y colectivos para favorecer que las empresas y los destinos turísticos mejoraran su competitividad ${ }^{15}$. En el año 2009 se publicó el Atles del Turisme a Catalunya. Mapa Nacional de l'Oferta i els Productes Turístics ${ }^{16}$. La Agència Catalana de Turisme (ACT) se creó en el año 2010 como organismo público-privado encargado de llevar a cabo las políticas de promoción turística. La ACT está constituida por la Generalitat y por el Consejo General de Cámaras de Comercio de Cataluña, en representación del sector privado. Entre las entidades territoriales, están los patronatos de Turismo de las Diputaciones de Barcelona, Tarragona, Lleida y Girona, así como la entidad mixta público-privada Turisme de Barcelona ${ }^{17}$. En este año también se creó la Comisión Interdepartamental de Turismo ${ }^{18}$. Son funciones de esta Comisión impulsar y coordinar bajo una estrategia integrada las acciones en materia de política turística que, por su transversalidad, afecten a varios departamentos de la Generalidad, hacer el seguimiento y proponer modificaciones de la normativa sectorial que incide sobre el turismo e impulsar los programas del Plan estratégico de turismo en los que sea necesaria la actuación coordinada de varios departamentos. En este año se aprobaron los Decretos 183/2010, de 23 de noviembre, de establecimientos de alojamiento turístico, y el 164/2010, de 9 de noviembre, de regulación de las viviendas de uso turístico ${ }^{19}$.

En el año 2011 se creó la Mesa de Turismo de Cataluña con el objetivo de ser una plataforma de interlocución con el sector, donde los agentes públicos y privados que inciden en la actividad turística participen de manera estable y permanente para cooperar en la definición y ejecución de las políticas en este ámbito ${ }^{20}$. En el año 2012 se aprobó el Decreto 158/2012 que modifica el Decreto 168/1994 de Reglamentación de las Agencias de Viajes de Cataluña, la Orden EMO / 418/2012, de 5 de diciembre, de estructuración del sistema catalán de calidad turística y la Resolución EMO / 1263/2012, de 14 de junio, por la que se aprueban las bases para la participación en el proceso selectivo para el acceso a la habilitación de guía de turismo de Cataluña.

15 Ordre IUE/254/2008, de 22 de maig, sobre la convocatòria per a la concessió d'incentius en l'àmbit del Pla de desenvolupament turístic. En el año 2008 se destinaron un total de 7,99 millones de euros a proyectos turísticos incentivados. El en año 2009 se destinaron 6,33 y 7,55 en el 2010.

16 Mediante la realización del "Atles" se ha pretendido conseguir una información integrada y territorializada de la oferta y los productos turísticos del conjunto de Cataluña, disponer de una visión integradora de las capacidades actuales y futuras y de las carencias de atractivo turístico de un territorio concreto, disponer de una herramienta de gestión para identificar actuaciones prioritarias y facilitar la coordinación y la colaboración interadministrativa sectorial e intersectorial (López-Palomeque, 2009).

17 Durante el primer año de gestión, la ACT organizó más de 300 acciones estratégicas de promoción, algunas de ellas muy significativas, como los Años de Cataluña en otros países o el macroworkshop de comercialización Buy Catalunya, iniciativas que se mantienen cada año (Agència Catalana de Turisme, 2012).

18 Decret 46/2010, de 30 de març, pel qual es crea la Comissió Interdepartamental de Turisme.

19 Posteriormente modificados por Decreto159/2012, de 20 de noviembre, de establecimientos de alojamiento turístico y de viviendas de uso turístico.

20 Decret 420/2011, de 20 de desembre, de creació de la Taula del Turisme de Catalunya (DOGC 6030 de $22 / 12 / 2011)$ 
Dentro de las acciones del primer plan, se crearon los Centros de Acogida Turística de Cataluña (CAT's) ${ }^{21}$, que pretendían ser una evolución de los puntos de información convencionales de las oficinas de turismo. También se diseñaron Las rutas nacionales de Cataluña, como Pirineo condal o Camí de Sant Jaume, se trazaron otras rutas para promocionar el patrimonio natural, histórico o cultural y se publicó el libro sobre los 116 símbolos iconográficos de la identidad catalana que ayudan a proyectar Cataluña en el ámbito del turismo. La irrupción de la crisis frenó el proceso de construcción y puesta en marcha de los CATs y de las grandes rutas nacionales, lo cual ha generado una cierta percepción de fracaso para ambas acciones. La implementación de las acciones derivadas del primer Plan Estratégico de Turismo perdió fuerza con la crisis de 2008, situación que se prolongó debido a los cambios de gobierno y la adaptación de la política turística al nuevo escenario (López-Palomeque y García, 2016).

En el segundo Plan Estratégico de Turismo, para el periodo 2013-2016, se establecen cinco programas ${ }^{22}$, que a su vez están constituidos en dieciséis subprogramas y treinta y siete proyectos que tienen como misión alcanzar los retos del plan. En diciembre de 2015 se presentó en el Consejo de la Mesa de Turismo de Cataluña el informe sobre el balance de ejecución del plan, con un seguimiento de sus programas, en el cual se indicaba que se habían alcanzado catorce de los programas previstos, once estaban en fase de ejecución, siete en fase de planificación, dos estaban pendientes de ejecución y el resto en proceso de reorientación ${ }^{23}$ (Direcció General de Turisme, 2016).

Entre las acciones del actual Plan destaca la puesta en marcha del primer Plan de Marketing Turístico 2013-2015 por parte de la Agencia Catalana de Turismo. La visión del turismo que se enmarca en este Plan de Marketing es conseguir una marca Cataluña más poderosa y un turismo más rentable. Con esta visión las acciones se orientan hacia la fidelización y captación de los turistas, priorizar las actuaciones de marketing online, potenciar las acciones de la red de oficinas del exterior ${ }^{24}$ y mejorar la colaboración y la coordinación entre los sectores público y privado. Para ello, durante este periodo se ha puesto en funcionamiento el portal turístico oficial, catalunya.com. En el año 2014 se presentó la plataforma de comercialización digital experience.catalunya.com, que permite comercializar paquetes turísticos de agencias de viajes y de otras empresas del sector con el doble objetivo de ayudar a la internacionalización de las PYMES turísticas y al mismo tiempo alcanzar un mayor equilibrio territorial del turismo mediante la priorización de las experiencias de la Cataluña interior. Para alcanzar una mayor diversificación de los mercados emisores internacionales se ha realizado una búsqueda de las agencias más adecuadas en cada uno de los países (por ejemplo Tripadvisor, Expedia o Atrapalo entre otras). El Plan ha priorizado la promoción turística a través de las redes sociales y la comunicación

21 Dictamen 276/2010 Projecte de decret de regulació de la Xarxa de Serveis d'Informació, Difusió i Atenció Turística de Catalunya.

22 1. Un proyecto de país internacional. 2. Cataluña, destino de destinos. 3. El producto, base del marketing. 4. Una dirección de turismo transversal. 5. Excelencia. Formación, innovación, idiomas y nuevas tecnologías como elementos clave para la excelencia.

23 Entre los proyectos no realizados se incluye el establecimiento del Pacto Nacional para el Turismo y la creación del servicio de acompañamiento a empresas emprendedoras e inversoras (CREATUR).

24 Actualmente la ACT dispone de una red de 12 oficinas en el exterior para la promoción internacional de la marca turística Cataluña (Agència Catalana de Turisme, 2017). 
mediante los canales online, con contenido multimedia altamente atractivo y adaptado a las preferencias del consumidor. Tras la finalización del primer Plan de Marketing Turístico, la ACT evaluó las actuaciones ejecutadas con la finalidad de obtener el grado de implementación del plan, que se situó en un 60\% (Agència Catalana de Turisme, 2017).

En el primer plan la Secretaria de Comercio y Turismo tenía previsto destinar un presupuesto de 180 millones de euros para el desarrollo de sus acciones, a los que se añadía un presupuesto inicial de 179 millones procedentes de los Patronatos provinciales y Turismo de Barcelona. En el segundo plan se estimaba un presupuesto de casi 16 millones de euros destinado a la ejecución de las acciones previstas. Sin duda, el recorte presupuestario que se observa entre ambos planes se debe a la política restrictiva que se aplicó durante la crisis económica y que afectó a los presupuestos públicos a partir del año $2011{ }^{25}$.

No obstante, desde el año 2012 esta menor dotación presupuestaria se compensa parcialmente con la recaptación del Impuesto sobre las estancias en establecimientos turísticos en Cataluña (tasa turística) (Ley de la Generalitat de 5/2012 de 20 de marzo), que supuso una novedad en el sistema tributario español ${ }^{26}$. Los recursos generados por la aplicación del impuesto alimentan el Fondo Para el Fomento del Turismo y se destinan a: a) promoción turística, b) impulso del turismo sostenible, responsable y de calidad y protección, preservación, recuperación y mejora de los recursos turísticos, c) fomento, creación y mejora de los productos turísticos, d) mejora de los servicios de control e inspección sobre los establecimientos y equipamientos turísticos e) desarrollo de infraestructuras y servicios relacionados con el turismo. Objetivos que, como hemos visto, persigue el segundo Plan Estratégico de Turismo. La Generalitat recaudó 174,5 millones de euros en los cinco primeros años (2012-2016) de aplicación de la tasa turística, según los datos de la Direcció General de Turisme (2017).

A pesar de las reticencias y reservas que la tasa generó inicialmente por parte del sector, que la consideró, no sólo innecesaria, sino que la vio como una amenaza que perjudicaría gravemente la competitividad del destino catalán con respecto a sus competidores (Colom et al., 2016a, Diari de Girona, 2012), durante los primeros años de singladura su aplicación ha sido satisfactoria. Su recaudación ha permitido hacer una promoción turística que, de otro modo, no habría sido posible por los problemas presupuestarios, y al mismo tiempo, no ha supuesto un freno a la entrada de turistas. Como indican García et al. (2018), desde su implantación en 2012, tanto el número de visitantes como los ingresos generados por el impuesto han presentado un crecimiento positivo. A semejante conclusión llega el estudio de Duro (2014).

25 La reforma del artículo 135 de la Constitución española, aprobada el 27 de septiembre de 2011, establece que todas las administraciones públicas han de adaptarse al principio de estabilidad presupuestaria y se determina por ley el déficit estructural máximo para el Estado y las autonomías en relación al PIB, lo cual queda regulado por la Ley Orgánica 2/2012, de 27 de abril, de estabilidad presupuestaria y sostenibilidad financiera.

26 El impuesto se creó mediante la Ley 5/2012, de 20 de marzo, de medidas fiscales, financieras y administrativas y de creación del impuesto sobre las estancias en establecimientos turísticos. El Decreto 161/2013, de 30 de abril, aprobó el reglamento del Fondo para el fomento del turismo. Posteriormente, la Ley 5/2017, de 28 de marzo de medidas fiscales, administrativas, financieras y del sector público y de creación y regulación de los impuestos sobre grandes establecimientos comerciales, sobre estancias en establecimientos turísticos, sobre elementos radiotóxicos, sobre bebidas azucaradas envasadas y sobre emisiones de dióxido de carbono, derogó el título III (artículos 98 a 116) de la Ley 5/2012. 
A partir de los datos del cuadro 1, donde se describen los objetivos de los Planes Estratégicos de Turismo aplicados hasta el presente, véase que hay una serie de aspectos que son recurrentes en ambos planes, como son:

- la colaboración público-privada

- la ordenación y planificación del territorio

- la mejora de la calidad y la innovación

- la sostenibilidad económica, social y cultural

- la creación de nuevos productos y experiencias turísticas

- la formación de los puestos de trabajo

- el uso de las TIC.

Diríase, pues, que son aspectos que merecen una especial atención y priorización, que además condicionan el desarrollo del sector turístico y que deben afrontarse con un enfoque decidido para facilitar su alcance a medio plazo. Tras su identificación es necesario tenerlos muy en cuenta y realizar una clara apuesta para aportar propuestas de mejora.

Al respecto, cabe destacar que muchas de las acciones previstas en los planes de actuaciones de ambos planes se han centrado en estos aspectos prioritarios, sin embargo, muchos de estos aspectos siguen siendo asignaturas pendientes del turismo en Cataluña aún hoy en día y deben ser objeto de atención en el próximo Plan Estratégico de Turismo.

\section{ORIENTACIONES DE LA POLÍTICA TURÍSTICA PARA UN FUTURO PLAN ESTRATÉGICO}

Actualmente, se detectan nuevas tendencias en el ámbito del turismo que no se observaban, o bien se situaban en una fase embrionaria, en el periodo de elaboración del segundo Plan Estratégico de Turismo en Cataluña. Veamos cuales son para que sean consideradas como retos en próximas planificaciones turísticas.

Aunque el segundo plan ya apuntaba la existencia de un número de "plazas de alojamiento de viviendas de uso turístico no regularizado superior a un millón de camas" (Generalitat de Cataluña, 2013, p.8), este es uno de los problemas candentes que actualmente se observa en determinados destinos turísticos de Cataluña y con mayor intensidad en la ciudad de Barcelona. La primera causa de congestión declarada por los ciudadanos, en destinos vacacionales y urbanos de éxito es el desbordante, irregular y aún descontrolado crecimiento de la oferta de viviendas turísticas distribuidas por plataformas, que en apenas seis años superan toda la oferta reglada existente, según datos de Exceltur (2017).

El éxito experimentado por las plataformas de economía colaborativa en el sector del alojamiento turístico, que ofrecen una alternativa a los sistemas tradicionales de hospedaje, tiene un claro exponente en la empresa Airbnb ${ }^{27}$. En ella, los propietarios ceden el uso de sus viviendas (o habitaciones) a terceros a cambio de una prestación económica con carácter puntual o esporádico. No obstante, el modelo colaborativo también incluye fórmulas sin ánimo de lucro, en las que se ceden habitaciones o viviendas de forma gratuita o se

27 El estudio de Fuster et al. (2017) apunta que Airbnb ofertaba en el año 2017 un total de 17.370 alojamientos en la ciudad de $\mathrm{BCN}$, de los que solo el $22 \%$ tenían licencia para operar. 
intercambian entre los usuarios de la plataforma (por ejemplo, Couschsurf o Homeforexchange). Ahora bien, la irrupción de este pujante mercado de viviendas de uso turístico no está exenta de fricciones. Entre ellas, Herrero (2017) destaca las siguientes. Se acusa a los nuevos operadores de no competir en el mercado turístico con las mismas reglas que compiten el resto de agentes del sector. Se identifican problemas de seguridad ante la existencia de un tráfico importante de personas sin control, problemas de convivencia en las comunidades de vecinos debido al ruido o suciedad, aumento de la economía sumergida, violación de los derechos de los consumidores en materia de seguridad y calidad de los productos y la degradación de la imagen del destino turístico. Por último, señala que en ciudades como Barcelona, uno de los principales problemas es la retirada del mercado de alquiler, de larga duración o residencial, de las viviendas situadas en zonas de especial atractivo turístico, dado que resulta más rentable el alquiler por días o semanas que el alquiler residencial de largo plazo. De este modo, la contracción de la oferta conduce a un encarecimiento de los precios de los alquileres. Se produce, por ello, un proceso de gentrificación, debido a que la llegada de turistas desplaza a la población tradicional hasta el punto de excluirla definitivamente del territorio (González, 2011), lo cual supone un nuevo reto para los destinos turísticos. En la ciudad de Barcelona este fenómeno se detecta, con mayor o menor intensidad, en los barrios de la Barceloneta, Raval, San Antonio, Gràcia, Sants o Poble Nou (Crespi-Vallbona y Mascarilla-Miró, 2018).

Los nuevos modelos de negocio que surgen de la economía colaborativa tienen un impacto significativo en otras actividades turísticas como el transporte, restauración o comercio. La eclosión de la economía colaborativa ha supuesto, en algunos casos, que la oferta disponible y accesible a través de las plataformas sustituya buena parte de la oferta tradicional. Así, por ejemplo, los taxistas han notado el efecto de los servicios de transporte con licencias de vehículos de turismo con conductor (VTC) prestados por empresas como Cabify o Uber. Ello ha motivado la convocatoria de huelga, por parte de los taxistas de ciudades como Barcelona (en julio de 2018 y enero de 2019), en protesta para conseguir que se limite el número de licencias de vehículos de alquiler con conductor (VTC).

El conflicto surge ante la falta de una legislación general (en el ámbito autonómico, español o europeo) que regule las actividades de la economía colaborativa, lo cual lleva a que las nuevas empresas operen con normativas distintas en cada territorio. Ello es interpretado por las empresas tradicionales como una cierta permisividad hacia las nuevas plataformas que no asumen las mismas responsabilidades laborables, de seguridad o fiscales (Exceltur, 2016b). En otro ámbito, el Comité Económico y Social Europeo (2016), señala que ciertos negocios utilizan de forma indebida la denominación de economía colaborativa para eludir la normativa aplicable. En definitiva, se constata que las nuevas tecnologías han facilitado a la economía colaborativa la creación de nuevos modelos de negocios turísticos. En este marco de economía colaborativa, tampoco podemos olvidar el empoderamiento de los consumidores a través de los sistemas de calificación del servicio y de revisión que les permite contribuir en cierto modo a una regulación del comportamiento empresarial y la competencia (Leal y Medina, 2018). Sin embargo, uno de los retos del próximo plan estratégico es evitar que los negocios turísticos que surjan al amparo de la economía colaborativa sean una competencia desleal para los operadores tradicionales. 
Las nuevas tecnologías aportan otros recursos al sector turístico, como por ejemplo la tecnología móvil, para contratar y resolver muchos trámites relacionados con los viajes, servicios basados en la geolocalización o como sistemas de pago, la realidad virtual, que permite las visitas virtuales, buscadores que permiten comparar servicios y precios o la inteligencia artificial mediante el uso de chatbots para mejorar la comunicación con el cliente. Junto a estas, existen otras tecnologías que en los próximos años impulsaran el desarrollo del turismo como la robótica, internet de las cosas, blockchain o big data (OMT, 2018). Al respecto, el informe de Ureña (2015) destaca que el objetivo central de la política de turismo europea es la competitividad. Por ello, la Comisión reconoce la importancia de la innovación, la investigación y las Tecnologías de la Información y Comunicación en la competitividad del turismo. La referencia a la investigación e innovación, por parte de la UE, también se constata en la Estrategia de Investigación e Innovación para una Especialización Inteligente (RIS3) que aprobó el Consejo de la UE en 2013, para el periodo 20142020. Su objetivo es convertir la innovación en una prioridad para todas las regiones. La aplicación del RIS3 requiere que las regiones de la UE identifiquen las especializaciones de conocimientos que mejor se ajustan a su potencial de innovación, basándose en sus activos y capacidades (Comisión Europea, 2013).

Para el caso de Cataluña, mediante el RIS3CAT, se identificaron siete ámbitos sectoriales líderes que, en base a su peso y potencialidad, pueden actuar como activadores de la reorientación de la economía catalana hacia un modelo de crecimiento más inteligente, sostenible e integrador. Uno de los siete ámbitos es el de las industrias basadas en la experiencia, que incluye las industrias creativas y culturales y servicios como el turismo y los deportes. Como destaca el RIS3CAT, el turismo tiene una gran capacidad de tracción del resto de sectores (Industrias culturales, comercio, servicios de salud y construcción) y es un factor clave de dinamización de zonas rurales. La red de parques naturales también tiene una elevada capacidad para integrar actividades procedentes de diversos sectores y generar economías de escala. A nivel internacional, el posicionamiento de la marca Barcelona es un activo clave para el turismo y las industrias culturales y creativas: capital del diseño, la moda, la gastronomía, la arquitectura y la creatividad; capital del deporte (FC Barcelona, juegos olímpicos); ciudad de congresos, ferias y festivales internacionales; capital mediterránea; ciudad de negocios (escuelas de negocio de élite, multinacionales, congresos) y calidad de vida. Las tendencias globales en el turismo generan nuevas oportunidades económicas) las nuevas clases medias de los países emergentes piden servicios turísticos; el envejecimiento de la población genera una demanda creciente de servicios adaptados, que es menos estacional (Generalitat de Cataluña, 2018). La economía de experiencias en la que se encuentra inmerso el sector del turismo, busca modos de satisfacer las vivencias que el consumidor reclama a través de tipologías turísticas que exalten las sensaciones (Araújo, 2015).

Otro de los retos que debería afrontar el próximo plan estratégico es adecuar la llegada de turistas a la capacidad de carga de los destinos turísticos (monumentos, espacios protegidos, servicios de limpieza, contaminación del aire, playas, vías de transporte, etc.) y evitar la congestión estacional (en agosto, por ejemplo). Crosby (2018) señala que superar la carga física y emocional del destino, conlleva necesariamente a una fobia 
hacía los resultados o impactos negativos de esta actividad mal gestionada y convertirse en turismofobia.

En Barcelona es donde se detecta una mayoría de ciudadanos que creen que hay que limitar el turismo. Según el informe de Actividad Turística 2016 publicado por el Ayuntamiento de esta ciudad, por primera vez el porcentaje de residentes que creen que se ha llegado al límite para dar servicio al turista $(48,9 \%)$ supera el porcentaje de residentes que creen que la ciudad de Barcelona debe atraer más turismo (47,5\%) ${ }^{28}$. Esta saturación del turismo que se detecta en Barcelona a partir de 2016 se intensifica en los meses posteriores con protestas contra la masificación turística durante el verano de 201729. El trabajo de Huete y Mantecón (2018) investiga este fenómeno a partir de la identificación y exploración de los discursos producido en los medios de comunicación durante el verano de 2017. Para ello la expresión turismofobia se ajusta a la aparición de actitudes de rechazo al turismo que van inexorablemente unidas a acciones mediante las cuales ese rechazo se hace públicamente manifiesto mediante ataques a infraestructuras diseñadas para el uso o consumo turístico, pintadas en paredes, concentraciones ciudadanas para protestar contra el turismo (o contra algún elemento distintivo de este), producción de material impreso y audiovisual para denunciar determinados aspectos de la actividad turística que se valoran negativamente. Los resultados indican que el auge de la turismofobia, que se manifiesta a partir de 2017, no se debe únicamente al hecho de haber superado la capacidad de carga de la ciudad de Barcelona, son relevantes también aspectos como la activación de un clima sociopolítico propicio, la percepción por parte de la ciudadanía de una mayor o menor dependencia económica respecto a determinadas tipologías turísticas y la ausencia de opciones alternativas de producción de riqueza, los comportamientos incívicos por parte de algunos turistas, la expansión y concentración del alojamiento turístico ilegal y la valoración desigual de los costes y beneficios resultantes del turismo.

Se observa que, en Cataluña, el número de turistas crece (INE, 2017) a la par que también crecen los conflictos en el uso del espacio. Por ello, aunque el segundo plan indica que el modelo turístico no tiene por objetivo incrementar la cifra de turistas, sino los ingresos y la mejora de la calidad del sector, sigue siendo necesario el análisis sobre la capacidad y sostenibilidad del actual modelo turístico. Urge pues la aplicación de acciones para alcanzar el reto de equilibrar la cantidad de turistas con la calidad del turismo. Los datos del informe publicado por el Ayuntamiento de Barcelona indican que año tras año la ciudad bate récords de turistas. Durante el año 2016 las pernoctaciones se incrementaron un 5,5\% respecto el año anterior, hasta llegar a los 19,5\% millones y los alojamientos en los hoteles de la ciudad se cifraron en 7,49 millones. Como señala Anguera-Torrell (2018), no tiene sentido que una parte importante de la recaudación de la tasa turística se destine a la promoción de Barcelona como destino. Debería utilizarse en actuaciones que beneficien e impacten positivamente en la ciudadanía (mejora en los transportes, construcción de equipamientos sociales, dinamización de otros sectores productivos, etc.) para hacer tangible los efectos positivos del turismo.

28 El porcentaje de vecinos que creen que la marca Barcelona ha tocado techo en cuanto a la capacidad de la ciudad para hacer frente al fenómeno del turismo pasó del 25\% al 48,9\% en cuatro años, del 2012 al 2016.

29 Los hoteleros de la Costa Daurada también han advertido del "riesgo" que la turismofóbia acabe llegando a Tarragona (La Vanguardia de 10/5/2018). 
La continuidad de este creciente impacto del turismo en la ciudad, llevará a reconsiderar una de las fortalezas que destaca el segundo plan: "La marca Barcelona es una de las más valoradas del mundo. El Gran éxito de Barcelona compensa en parte un modelo turístico basado en la explotación poco sostenible del litoral tanto en términos ambientales como económicos" (Generalitat de Cataluña, 2013, p. 13).

En este punto cabe destacar que en el último trimestre del año 2017 se detectó una ralentización de la actividad turística, cuyo descenso fue más acusado en la ciudad de Barcelona que en el resto del territorio catalán, según los datos proporcionados por el comunicado de la Dirección General de Turismo de la Generalitat, elaborado a partir de las estadísticas del INE. Del mismo modo, los datos de Exceltur (2019) para el año 2018, indican que los resultados del turismo siguen cayendo no solo en Barcelona, también en destinos de sol y playa, como la Costa Brava, La Costa del Garraf o la Costa Dorada. La rentabilidad de las empresas turísticas catalanas se vio reducida en un 70,2\% de los casos respecto al año 2017, según la Encuesta de Clima Turístico Empresarial que realiza Exceltur. Entre otros aspectos, que explican dicha situación, se destaca la recuperación de los mercados competidores del Mediterráneo Oriental, como Turquía, Egipto o Túnez.

Respecto a los factores causantes del menor atractivo internacional de la marca Barcelona cabe destacar, junto a los comentados anteriormente, la huelga de los trabajadores del control de seguridad del aeropuerto del Prat, los atentados terroristas de la Rambla y las incertidumbres por la situación política y social en Cataluña durante 2017, la huelga del servicio de limpieza del aeropuerto del Prat en 2018, las movilizaciones de Taxis y VTC o la huelga del metro durante el Mobile World Congress en 2019. Ante este nuevo panorama el futuro Plan Estratégico de Turismo debe adoptar medidas bien orientadas que permitan consolidar la buena imagen turística que la marca Barcelona tenía hasta el momento. Es necesario demostrar que la ciudad sigue siendo segura e interesante para acoger visitantes y recibir inversiones. Para ello es precisa una campaña de promoción conjunta entre Turismo de Barcelona (la entidad de promoción turística de la ciudad) y la Dirección General de Turismo de la Generalitat, que sea capaz de atraer congresos, convenciones y, en definitiva, turismo de alto valor añadido.

De lo anterior se desprende otro reto, el encaje entre el futuro Plan Estratégico de Turismo en Catalunya y el segundo Plan Estratégico de Turismo de la ciudad de Barcelona 2020, aprobado en marzo de 2017, que destaca la necesidad de gestionar el turismo para garantizar el interés general de la ciudad, asegurando al mismo tiempo la sostenibilidad del destino. De este modo, el Plan evidencia la necesidad de establecer parámetros y objetivos de desarrollo de la actividad turística que garanticen una convivencia pacífica con los residentes.

Otro de los retos que debería asumir el próximo Plan Estratégico de Turismo es el de los costes laborales de los empleados del sector. Como hemos visto, en ambos planes se hace referencia a la necesidad de potenciar la formación especializada y continuada como herramienta para alcanzar una mayor calidad en los puestos de trabajo del sector. No obstante, esta alusión a la mejora de la calidad en la ocupación, no siempre viene acompañada de una mejor retribución. Los datos de la Encuesta de Población Activa, publicados por el INE, muestran que Comercio y Hostelería son las actividades que más empleo están creando desde 2014 cuando se inició la recuperación del ciclo económico. 
En su estudio, la Confederación Sindical de Comisiones Obreras (2018), afirma que en el periodo (2t2013-2t2017) uno de cada cinco empleos netos se ha creado en la Hostelería, aumentando su peso en el empleo total. Si a esta, se añade la actividad del Comercio, entre ambas concentraban un tercio del empleo asalariado creado. Paralelamente, los datos estadísticos publicados por el INE sobre la Encuesta Anual de Costes Laborales, para los años 2016 y 2017, indican que estas actividades obtuvieron los costes laborales anuales más bajos (INE, 2017 y 2018). Las actividades turísticas, excepto las relacionadas con el transporte, se caracterizan de forma estructural, por tener costes laborales siempre inferiores a los del sector servicios y el total de la economía nacional, debido a un menor nivel salarial en estas actividades (INTELITUR, 2015).

Junto a los bajos sueldos del empleo en el sector turístico, las reformas laborales de los últimos años de la crisis han favorecido una mayor precariedad laboral. Según los datos de la EPA (que publica el INE), en 2017, menos de la mitad de la población afiliada al régimen general ha contado con un contrato indefinido a jornada completa $(47,9 \%)$ y la mayoría $(52,1 \%)$ presentaba algún tipo de precariedad: contrato temporal y/o trabajo por horas. Desde 2010 está cayendo el peso de la afiliación con contrato indefinido a tiempo completo, primero por el avance de la jornada parcial y desde 2014 por el repunte de los empleos temporales, según denuncian los sindicatos de trabajadores como la Confederación Sindical de Comisiones Obreras (2018) y la propia OIT (2018), que en su informe indica que el empleo a tiempo parcial representa más de una cuarta parte del crecimiento neto del empleo desde 2015 y la proporción de trabajadores a tiempo parcial involuntarios supera el $60 \%$. En este punto, es necesario destacar que sin calidad del empleo no se alcanzará la calidad y la excelencia del turismo que se pretende en los planes de turismo aprobados. Aun siendo cierto que el turismo emplea en términos generales mano de obra poco calificada ${ }^{30}$, sin un empleo de calidad no se puede ofrecer un servicio de calidad.

\section{CONCLUSIONES}

Como se ha visto a lo largo del artículo, Cataluña es uno de los primeros destinos turísticos de Europa con una realidad compleja, que López-Palomeque y García (2016) resumen con las siguientes características: El turismo tiene un carácter estructural. La actividad turística es estacional y se concentra en verano. El mapa turístico de Cataluña es asimétrico, con una fuerte concentración de las actividades en el litoral. El flujo turístico es diversificado. Pese a la hegemonía del turismo de sol y playa, existe una diversidad de turismos. Participación activa de los agentes públicos y privados. El turismo es un factor estructurador del territorio. El modelo turístico es dinámico y se adapta a las nue-

30 El estudio sobre el empleo en el sector turístico español, indica que "el contacto directo y la relación personal en la prestación de la mayoría de servicios de las ramas vinculadas al turismo explica que la mayor parte del empleo se concentre en puestos de trabajo de base, en comparación con otros sectores de actividad. Este rasgo hace que el turismo sea uno de los sectores que presenta una mayor concentración de empleados en los grupos inferiores de la clasificación por categorías de la Seguridad Social correspondiente a dichos empleados de base; un $89,8 \%$, sólo superado entre los grandes sectores de la economía española por la agricultura, con un 93,1\%" (Exceltur, 2018, p.18). 
vas realidades. Existen zonas turísticas consolidadas e institucionalizadas como unidades operativas para la administración pública turística. Cataluña es un destino maduro.

Todo ello confiere al turismo en una de las prioridades estratégicas de la economía catalana y justifica el objetivo de nuestro trabajo. En él, se han revisado los avances y nuevas tendencias de este sector, desde la aprobación del primer Plan Estratégico de Turismo para el periodo 2005-2010 hasta la actualidad donde aún sigue vigente el segundo Plan Estratégico 2013-2016 y Directrices Nacionales de Turismo 2020, lo cual nos ha permitido hacer propuestas a incluir en el próximo Plan Estratégico de Turismo a partir del enfoque del Análisis de Política Públicas, habida cuenta que la planificación de la política turística se erige como el instrumento que marca la hoja de ruta.

El segundo Plan Estratégico de Turismo pretende alcanzar el reto de incrementar los indicadores de calidad del turismo mediante una propuesta sostenible y competitiva que transforme parte de la oferta obsoleta y madura de este destino turístico. Los indicadores de competitividad del turismo en Cataluña han mostrado un avance de 16 puntos porcentuales durante el periodo 2010-2014. Al tiempo que se reducía la valoración en Ordenación y condicionantes competitivos del espacio turístico en el que se valora aspectos como la densidad urbanística de los destinos o el compromiso ambiental (tratamiento de residuos, depuración de agua, gestión ambiental de playas o calidad del aire).

El segundo Plan Estratégico revela ciertos problemas turísticos que aún siguen vigentes y han tomado una mayor dimensión. Entre ellos cabe destacar la creciente oferta de viviendas turísticas irregulares distribuidas por plataformas tecnológicas, la formación de los recursos humanos del sector, la apuesta por un turismo de mayor valor añadido o la sostenibilidad en términos económicos, culturales y ambientales. A lo anterior cabe destacar que la crisis impuso un giro en la asignación económica de las acciones a desarrollar previstas en este segundo plan, en una coyuntura en la que ha sido necesario encontrar estrategias para alcanzar un mayor crecimiento económico con el que superar la crisis y el turismo era una de estas estrategias.

Ante las diferentes necesidades de los agentes turísticos y otros agentes económicos, no siempre compartidas, el reto del tercer Plan Estratégico de Turismo es complejo. Sin embargo, a lo largo del estudio se ha puesto de relieve que existen aspectos y tendencias que no pueden dejarse de lado. Entre ellos cabe destacar la congestión de determinados destinos turísticos, causada por factores como la excesiva oferta de viviendas turísticas que genera un negativo impacto sobre la calidad de vida de los residentes, o la excesiva presión humana que genera una saturación de la capacidad de carga turística. El dinamismo de la economía colaborativa y su convivencia con los agentes turísticos tradicionales. El impulso del desarrollo y la competitividad del turismo a través de la innovación, la investigación y las nuevas tecnologías. El equilibrio entre la calidad del turismo y la cantidad de turistas que acoge el territorio, lo cual facilitará la consolidación de las marcas turísticas catalanas. Sin olvidar una mejora de las condiciones laborales de los empleados del sector. Se observa que estos aspectos afectan a los destinos turísticos y también a los agentes turísticos, como son las empresas turísticas, los trabajadores del sector, los turistas y la propia sociedad. Así pues, y como constatan Santos-Lacueva et al. (2017) la intervención pública en la actividad turística es necesaria para paliar los efectos negativos que genera el turismo y que el mercado no es capaz de corregir por sí mismo. 


\section{BIBLIOGRAFÍA}

AGÈNCIA CATALANA DE TURISME (2012): Memòria 2012 Agència Catalana de Turisme. Barcelona, ACT.

AGÈNCIA CATALANA DE TURISME (2017): Memòria 2017 Agència Catalana de Turisme. Barcelona, ACT.

ALEDO, A. (2008): “De la tierra al suelo: la transformación del paisaje y el nuevo turismo residencial", Arbor, vol. 184, n 729, pp. 99-113.

ANGUERA-TORRELL, O. (2018): "El turismo no es problema", Noticias del CETT-UB, Campus Internacional de formación y transferencia de conocimiento en turismo. Disponible en https://www.cett.es/es/sala-de-prensa/noticias/detalle/263048

ARAÚJO, N. (2015): "De la economía de experiencias al turismo experiencial. Las series de acción como creadoras de experiencias e inductoras a la visita de destinos turísticos", Pasos. Revista de Turismo y Patrimonio Cultural, vol. 13, n 4, pp. 959-964.

ARNANDIS-I-AGRAMUNT, R. (2018): “Una revisión a la planificación de los recursos: sobre los enfoques de evaluación y los modelos de adaptación al uso turístico", Investigaciones Turísticas, ${ }^{\circ}$ 15, pp. 168-197.

AYUNTAMIENTO DE BARCELONA (2017): Actividad Turística 2016. Barcelona, Ayuntamiento de Barcelona.

BALAGUÉ CANADELL, J. y NAVINÉS BADAL, F. (2012): “Sistema de indicadores para la gestión sostenible de un destino turístico: aplicación a la Costa Brava centro", Harvard Deusto Busines Research, vol.1, n 2, pp.132-146.

BANCO MUNDIAL (2006): Evaluación de Efectos de los Programas Sociales. Perspectivas de las Políticas Públicas. Banco Mundial.

BARÓ, E. (2010): Estimació de l'impacte total de la despesa turística corrent a Catalunya en el conjunt de l'economia $i$ en els seus principals sectors d'activitat. Aplicació d'una metodologia input-outupt. Barcelona, Generalitat de Catalunya, Departament d'Innovació, Universitat i Empresa.

CÀNOVES, G., PRAT, J.M. y BLANCO, A. (2016): “Turismo en España, más allá del sol y la playa. Evolución reciente y cambios en los destinos de litoral hacia un turismo cultural”, Boletín de la Asociación de Geógrafos Españoles, no 71, pp. 431-454.

COLOM, M., FONT, J. e IMBERT-BOUCHARD,D. (2016a): "La sostenibilidad económica de la promoción y el fomento del turismo: el impuesto sobre las estancias en establecimientos turísticos (IEET) promovido por el Gobierno de Cataluña", Ara Journal of Tourism Research, vol. 6, $\mathrm{n}^{\circ}$ 2, pp. 21-32.

COLOM, M., FONT, J. e IMBERT-BOUCHARD,D. (2016b): "La sostenibilitat econòmica de la promoció i el foment del turisme: l'impost sobre las estades en establiments turístics (IEET) promogut pel Govern de Catalunya", Comunicació. Smart Tourism Congress Barcelona CETT-UB.

COMISIÓN EUROPEA (2013): Estrategias nacionales y regionales para la especialización inteligente (RIS3). Unión Europea.

COMITÉ ECONÓMICO Y SOCIAL EUROPEO (2016): Dictamen sobre la Economía colaborativa y la autoregulación. DOUE C 303, DE 19 de agosto de 2016. 
CONFEDERACIÓN SINDICAL DE COMISIONES OBRERAS (2018): Informe de coyuntura laboral. Enero 2018. Madrid, Comisiones Obreras.

COTS, F., ROCA, E., BAEZA, L. y SALLENT, O. (2010): “Turismo activo y sostenibilidad en Cataluña. Una valoración desde el sector privado", Estudios Turísticos, n 183 , pp. 75-90.

CRESPI-VALLBONA, M. y MASCARILLA-MIRÓ, O. (2018): “La transformación y gentrificación turística del espacio urbano. El caso de la Barceloneta (Barcelona)", EURE, vol. 44, n 133, pp. 51-70.

CROSBY, A. (2018): Del sobreturismo a la turismofobia: Calidad y competitividad turística. Hosteltur. Disponible en https://www.hosteltur.com/comunidad/003095_delsobreturismo-a-la-turismofobia-calidad-y-competitividad-turistica.html

DEPARTAMENT D'EMPRESA I CONEIXEMENT (2011): "L'estacionalitat turística: causes i efectes". Departament d'Empresa i Coneixement. Notícies del Butlletí n ${ }^{\circ}$ 6, pp. 2-6.

DIARI DE GIRONA (2/6/2012): https://www.diaridegirona.cat/comarques/2012/06/02/ estudiant-gironi-contra-taxa-turistica-ilp/565309.html

DIRECCIÓ GENERAL DE TURISME (2016): Plec de prescripcions tècniques que regeixen la contractació d'una empresa que s'encarregui de l'actualització dels Plans Estratègic i de Marquèting de Turisme de Catalunya per al período 2017-2020. Barcelona, Generalitat de Catalunya, Departament d'Empresa i Coneixement.

DIRECCIÓ GENERAL DE TURISME (2017): Recaptació de l'impost sobre les estades en establiments turístics. Any 2016. Barcelona, Generalitat de Catalunya, Departament d'Empresa i Coneixement.

DURO, J.A. (2014): Les taxes turístiques com a instruments de política pública turística: el cas català en el marc de l'experiència internacional. Barcelona, Diputació de Barcelona.

DURO, J.A. (2015): “Aproximació a l'activitat económica generada pel turisme a les comarques de Catalunya. Sèrie 2008-2012 (i avenç 2013)". Departament d'Empresa $i$ Coneixement. Notícies del Butlletí $\mathrm{n}^{\circ} 23$, pp. 2-36.

DURO, J.A. y FARRÉ, F.X. (2015): "Estacionalidad turística en las provincias españolas: medición y análisis", Cuadernos de Turismo, n 36, pp. 157-174.

DURO, J.A. y RODRÍGUEZ, D. (2015): "Barcelona como municipio turístico: algunos datos evolutivos y elementos de futuro", Documents d'Anàlisi Geogràfica, vol. 61, $\mathrm{n}^{\mathrm{0}} 3$, pp. 507-538.

EUROPEAN CITIES MARKETING (2017). The ECM Benchmarking Report 2017. Dijon: ECM.

EUROSTAT (2017): Estadísticas sobre turismo. Eurostat.

EXCELTUR (2016a): Monitur 2014. Monitor de competitividad turística relativa a las comunidades autónomas españolas. Exceltur.

EXCELTUR (2016b): El dilema de la economía colaborativa. Exceltur.

EXCELTUR (2017): "Informe perspectivas turísticas. Balance empresarial del segundo trimestre de 2017 y expectativas para el verano 2017”, Perspectivas Turísticas, ${ }^{\circ} 61$.

EXCELTUR (2018): Estudio sobre el empleo en el sector turístico español. Exceltur.

EXCELTUR (2019): "Valoración turística empresarial de 2018 y perspectivas para 2019”, Perspectivas Turísticas, $\mathrm{n}^{\circ} 67$. 
FUSTER, M.; CARBALLA, B.; SMORTO, G.; ESPELT, R.; IMPERATORE, P.; REBORDOSA, M.; ROCAS, M.; RODRÍGUEZ, N.; SENABRE,E. y CIURCINA, M. (2017): Multidisciplinary Framework on Commons Collaborative Economy. DECODE.

GABARDA, A., RIBAS, A. y DAUNIS-I-ESTADELLA, J. (2015): "Desarrollo turístico y gestión eficiente del agua. Una oportunidad para el turismo sostenible en la Costa Brava (Girona)", Investigaciones Turísticas, nº 9, pp. 50-69.

GARAY, LL. y CÀNOVES, G. (2009): "El desarrollo turístico en Cataluña en los dos últimos siglos: una perspectiva transversal”, Documents d'Anàlisi Geogràfica, nº 53, pp. 29-46.

GARAY, LL., GOMIS, J.M. y GONZÁLEZ, F. (2018): “El valor de la sostenibilidad como factor de diferenciación en los procesos de intermediación turística: un análisis para el caso de las pymes catalanas", Cuadernos de Turismo, no 41, pp. 219-248.

GARCÍA, A.M., MARCHENA, M.J. y MORILLA, A. (2018): "Sobre la oportunidad de las tasas turísticas: el caso de Sevilla", Cuadernos de Turismo, no 42, pp. 161-183.

GENERALITAT DE CATALUÑA (2013): Plan Estratégico de Turismo de Cataluña 20132016 y Directrices Nacionales de Turismo 2020. Barcelona, Generalitat de Cataluña.

GENERALITAT DE CATALUÑA (2018): RIS3CAT. Pla d'acció 2015-2020. Barcelona, Generalitat de Cataluña.

GERTLER, P.; MARTÍNEZ, S.; PREMAND, P.; RAWLINGS, L.B. y VERMEERSCH, C.M.J. (2011): La evaluación de impacto en la práctica. Banco Mundial.

GONZÁLEZ, S. (2011): "Bilbao and Barcelona "in motion”. How urban regeneration "models" travel and mutate in the global flows of policy tourism", Urban Studies, vol. 7, n 48, pp. 1397-1418.

HERRERO, C. (2017): "Las viviendas de uso turístico: ¿El enemigo a abatir? Reflexiones sobre la normativa autonómica en materia de alojamientos turísticos", Revista de Estudios Europeos, $\mathrm{n}^{\circ}$ 70, pp. 147-158.

HUETE, R. y MANTECÓN, A. (2018): El auge de la turismofobia ¿hipótesis de investigación o ruido ideológico?, Pasos, vol.16, nº 1, 9-19.

INE (varios años): Encuesta de Población Activa (EPA). Instituto Nacional de Estadística.

INE (2017): Estadística de movimientos turísticos en frontera. Instituto Nacional de Estadística.

INE (2018): Encuesta Anual de Coste Laboral (EACL). Instituto Nacional de Estadística. INTELITUR (2015): Costes laborales en las actividades turísticas. Segundo trimestre 2015. Centro de Conocimiento, Inteligencia e Innovación Turística.

IVALUA (2009): Col.lecció Iválua de guies pràctiques sobre avaluació de politiqees públiques. IVALUA.

LAVANGUADIA:Loshoteleros de la CostaDauradahacen autocríticadel estado de sus playas (10/05/2018): https://www.lavanguardia.com/local/tarragona/20180510/443473922437/ hoteleros-costa-daurada-hacen-autocritica-estado-playas.html

LEAL, M.P. y MEDINA, F.X. (2018): "Turismo y economía colaborativa: el caso de los recorridos gratuitos a pie en Barcelona", Cuadernos de Turismo, n 41, pp. 323-341.

LÓPEZ-PALOMEQUE, F.(Dir.) (2009): Atles del Turisme a Catalunya. Mapa Nacional de l'Oferta i els Productes Turístics. Barcelona, Universitat de Barcelona.

LÓPEZ-PALOMEQUE, F y GARCÍA, F. (2016): "Política turística y desarrollo del turismo en los espacios de interior de Catalunya", en OLCINA, J. y RICO, A.M. Libro 
Jubilar en Homenaje al Profesor Antonio Gil Olcina. Edición ampliada. Publicaciones de la Universidad de Alicante, pp. 1.311-1.328.

MIGUEL, A., SOLÍS, N. y TORRES, J.C. (2014): "El impacto territorial del turismo en el desarrollo sostenible: el caso de las regiones de México 2000-2010", Pasos. Revista de Turismo y Patrimonio Cultural, vol. 12, $\mathrm{n}^{\mathrm{o}}$ 2, pp.357-368.

NIÑO-BECERRA, S. (2015): La economía. Una historia muy personal. Barcelona, Ed. Los libros del lince.

OBSERVATORIO DEL TRABAJO Y MODELO PRODUCTIVO (2017): Balance turístico anual. Año 2016. Generalitat de Cataluña.

OCDE (2010): Estándares de calidad para la evaluación del desarrollo. OCDE.

OMT (2018): http://wtd.unwto.org/es/content/dmt-2018-tecnologia-en-el-turismoÇ

ORGANIZACIÓN INTERNACIONAL DE TRABAJO (OIT): Perspectivas sociales y del empleo en el mundo. Tendencias 2018. Ginebra, OIT.

RIVAS, J.I. (2017): Estructura y Economía del Mercado Turístico. Oviedo, Septem Ediciones.

ROMAGOSA, F.; PRIESTLEY, G.K. y LLURDÉS, J.C. (2011): "El turismo en el marco de una estrategia de planificación sostenible general en Cataluña”, Boletín de la Asociación de Geógrafos Españoles, $\mathrm{n}^{\circ}$ 57, pp. 447-454.

SABATÉ, X. (Coord.) (2007). Turismo sostenible: experiencias europeas aplicables a Cataluña. Barcelona. Consell Assessor per al Desenvolupament Sostenible.

SALA, M., TORRES, T. y FARRÉ, M. (2014): "La demanda turística de la economía española: caracterización y sincronización”, Cuadernos de Turismo, no 33, pp.335-356.

SANTOS-LACUEVA, R., CLAVÉ, S.A. y SALADIÉ, O. (2017): “Discontinuidades y limitaciones de los últimos planes turísticos de España en relación a la sostenibilidad ambiental del turismo de sol y playa", Cuadernos de Turismo, no 40, pp. 599-626.

SECRETARIA DE COMERÇ I TURISME (2005): Pla Estratègic del turisme a Catalunya 2005-2010. Barcelona, Generalitat de Catalunya.

SECRETARIA GENERAL DE TURISMO (2007): Plan del Turismo Español Horizonte 2020. Madrid, Ministerio de Industria, Turismo y Comercio.

SOLIGUER, A. (2017): "Gestión pública socialmente responsable del turismo en Cataluña”, Pasos. Revista de Turismo y Patrimonio Cultural, vol. 15, n 2, pp. 319-332.

TORRES-DELGADO, A. (2010): "Sostenibilitat i modalitats turístiques. Una anàlisi de casos a Catalunya", Documents d'Anàlisi Geogràfica, no 56, pp. 479-502.

TORRES, T., SALA, M. y FARRÉ, M. (2013): "El turismo sostenible en las marcas turísticas de Cataluña”, Revista Galega de Economía, no 22, pp. 51-72.

TORRES, T., SALA, M. y FARRÉ, M. (2015): “Grado de sostenibilidad de los ámbitos turísticos catalanes", Pasos. Revista de Turismo y Patrimonio Cultural, vol. 13, n 6 , pp. 1451-1462.

UREÑA, A. (Coord.) (2015): TIC y Turismo. Situación, políticas y perspectivas. Madrid, Ministerio de Industria, Energía y Turismo.

VELASCO, M. (2008): "Evolución de los problemas del turismo español. La Administración General del Estado como analista y los Planes públicos como indicadores (19522006), Papers de Turisme, no 43-44, pp. 7-31.

VELASCO, M. (2011): “La política turística. Una arena de acción autónoma”, Cuadernos de Turismo, $\mathrm{n}^{\circ}$ 27, pp. 953-969. 
